\title{
Otitis media aguda en pediatría
}

\author{
Vesta Richardson-López Collada, M.C., ${ }^{(1)}$ Rebeca Borgaro-Payró, M.C., ${ }^{(1)}$ \\ Liliana Jaramillo-Bernal, M.C., (2) Estela Fragoso-Cuéllar, M.C., ${ }^{(2)}$ \\ 0 scar Alberto N ewton-Sánchez, M.C., M. en C.(3)
}

\section{Definición y clasificación}

La otitis media aguda (OMA) es la infección supurada del oído medio, que tiene un inicio súbito y de corta duración; asimismo, denota inflamación de la cubierta mucoperióstica del oído medio. La membrana timpánica (MT) inflamada se presenta opacificada, protuyente o con ambas características.

Según su tiempo de evolución, la enfermedad puede subdividirse en: a) aguda, cuando el proceso dura no más de tres semanas; b) subaguda, cuando la infección perdura de tres semanas a tres meses, y c) crónica, cuando la enfermedad se prolonga durante más de tres meses. ${ }^{1}$

En el IV Simposio de Otitis Media que se llevó a cabo en julio de 1987 en Bal Harbour, Florida, se propuso la siguiente clasificación: ${ }^{2}$

1. Miringitis: cuando se trata de una inflamación de la capa externa de la MT que puede ocurrir sola o asociada a una inflamación del conducto auditivo externo.

2. Otitis media aguda supurada: cuando se trata de una infección aguda del oído con exudado y de corta duración.

3. Otitis media secretoria (otitis media serosa, otitis media crónica con derrame, otitis media mucosa): cuando hay presencia de líquido en el oído medio detrás de una membrana timpánica íntegra sin signos agudos o síntomas. En estos términos pueden incluirse aquellas otitis medias no supuradas o que clínicamente no presentan datos de infección.

4. Otitis media crónica supurada (otitis media crónica): cuando hay presencia de descarga crónica del oído medio a través de una perforación de la mem- brana timpánica. En algunos casos puede existir perforación sin descarga y tratarse de un estado inactivo de la infección.

\section{Epidemiología}

La OMA es un problema mundial de salud que afecta a uno de cada cuatro niños menores de 10 años y es la infección bacteriana más frecuente en niños menores de cinco años, de tal modo que constituye una de las causas más comunes de consulta médica pediátrica. De 25 a $40 \%$ de las visitas pediátricas en menores de cinco años son por OMA, mientras que en la edad adulta este padecimiento es raro.

La mayor parte de los estudios acerca de la OMA reflejan un pico en los primeros 24 meses de vida, que desciende conforme avanza la edad, probablemente debido a la relación inversa que la enfermedad mantiene con el riesgo de adquirir infecciones respiratorias altas, a una inmunocompetencia progresiva y a la angulación de la trompa de Eustaquio.

Hay estudios que indican que $80 \%$ de los prescolares menores de tres años han tenido cuando menos un episodio de otitis media, ${ }^{3}$ y que aproximadamente $46 \%$, tres o más episodios; se menciona que mientras más temprana es la presentación del episodio, existe un mayor riesgo de padecer otitis media crónica o recurrente.

En relación con la raza, parece que existen algunas diferencias en la prevalencia, pues esta última es mayor en blancos que en negros. ${ }^{4}$

En cuanto a las estaciones del año, prácticamente todos los estudios al respecto hacen referencia a que hay una mayor incidencia durante el otoño y el invierno.

(1) Departamento de Pediatría, Hospital del $\mathrm{N}$ iño Morelense, México.

(2) Departamento de 0 torrinolaringología Pediátrica, Hospital del N iño Morelense, México.

(3) Departamento de Infectología Pediátrica, Hospital del N iño Morelense, México. 
Otros factores que entran en juego son el bajo peso al nacer, la asistencia a guarderías infantiles -los niños que son llevados a guarderías parecen ser particularmente susceptibles a padecer otitis media-y la presencia de algún familiar fumador en la casa. ${ }^{5}$

Se ha observado que los pacientes con defectos estructurales o del desarrollo craneofacial tienen más episodios de OMA, aunados a procesos inflamatorios de las vías aéreas superiores (alergia o infección) y a hábitos inadecuados (lactancia en decúbito, sonarse en forma incorrecta, sumergirse en el agua inapropiadamente o en mal estado de salud cuando se practica la natación, etc.). ${ }^{1-5}$

\section{Fisiopatogenia}

El oído medio es parte de un sistema formado por la nasofaringe, la trompa de Eustaquio y la mastoides, estructuras que se encuentran recubiertas de epitelio respiratorio que contiene células ciliadas, secretorias de moco e inmunoglobulinas.

Entre las funciones del oído se incluyen la ventilación y el equilibrio de las presiones atmosféricas, así como la protección ante el sonido y el drenaje de secreciones a la nasofaringe. Cuando estos mecanismos se alteran, contribuyen a la proliferación bacteriana, lo que desencadena la infección. La obstrucción tubaria también inhibe el drenaje del líquido del oído medio a la nasofaringe, lo que contribuye al desarrollo de la infección.

La falla en estos mecanismos puede deberse a inflamación, infecciones frecuentes, problemas alérgicos o neoplásicos. Aunado a ello, la trompa de Eustaquio de los niños es más corta, más horizontal y tiene menor soporte cartilaginoso. ${ }^{6}$

\section{Etiología}

En dos terceras partes de los pacientes con OMA pueden aislarse patógenos bacterianos del líquido de oído medio. En 30-50\% de los casos se encuentra Streptococcus pneumoniae (serotipos 19, 23, 6, 14, 3 y 18). El Haemophilus influenzae causa entre 20 y $27 \%$ de los casos de OMA; la mayoría son cepas no tipificables. De 9 a $36 \%$ de estos casos son por $H$. influenzae tipo $b$, de los cuales la cuarta parte desarrolla bacteremia o meningitis. Por otra parte, Moraxella catarhallis se aísla en 7-23\% de los casos.

Otras bacterias que pueden causar OMA en menor porcentaje son: Streptococcus A, Staphylococcus aureus, Pseudomonas aeruginosa y Staphylococcus epidermidis.

Los niños hospitalizados desarrollan OMA por gérmenes del medio ambiente hospitalario. Asimismo los niños con tubos de ventilación pueden desarrollar infección por S. aureus, P. aeruoginosa y S. epidermidis. Cuando se aíslan Mycoplasma pneumoniae y Chlamydia pneumoniae en OMA se ha observado que se asocia a infecciones respiratorias bajas. Aproximadamente en $30-40 \%$ de los casos se detectan virus como el rinovirus, el virus sincicial respiratorio y los adenovirus.

\section{Cuadro clínico}

Casi todos los casos de OMA se presentan como un cuadro de coriza, rinitis, fiebre, tos, irritabilidad y anorexia. El síntoma más fidedigno es la otalgia. Los niños muy pequeños no verbalizan el dolor pero se jalan las orejas o rehúsan deglutir y lloran constantemente. Debe sospecharse cuando el dolor despierta a los niños por las noches.

\section{Diagnóstico}

El diagnóstico de OMA debe incluir una adecuada historia clínica y un examen físico completo, con énfasis en la inspección del oído medio, lo que sólo puede obtenerse mediante el uso de un otoneumatoscopio con perilla.

La otoneumatoscopía debe realizarse de manera que el conducto auditivo externo se encuentre libre para visualizar correctamente la membrana timpánica y valorar su movilidad, los cambios de coloración y vascularización, así como la presencia de niveles hidroaéreos por detrás de la misma.

La exploración clínica debe realizarse con un máximo de suavidad y cuidado, tanto para evitar dolor y mayor ansiedad en el paciente, como para permitir la observación de cualquier cambio de estructuras por pequeño que éste sea; debe usarse un otoscopio neumático con luz intensa y amplificación suficiente.

La exploración física no es sencilla en pacientes pediátricos, motivo por el cual debe tenerse paciencia y habilidad adquirida a lo largo del tiempo para realizarla.

La OMA se manifiesta clínicamente con retracción, eritema, disminución del reflejo luminoso e hipomovilidad de la membrana timpánica; asimismo, se presenta una disminución en la audición en rangos de baja frecuencia.

La membrana timpánica, particularmente la pars flácida, se encuentra hiperémica, con la vascularidad visible, y la pars tensa, abombada y turbia.

En un estado avanzado de inflamación puede haber ruptura de la membrana timpánica, habitualmente en la pars tensa, con salida de material francamente purulento, sanguinolento o seroso; la perforación habitualmente es pequeña, lo que la distingue de etiologías 
más raras (otitis necrosante, tuberculosis, recurrencia aguda de otitis media crónica), y una vez que el pus drena, los síntomas disminuyen de manera importante.

De manera ideal se debe realizar timpanometría para identificar diferencias en la presión dentro y fuera del oído y confirmar la presencia de líquido; asimismo la reflectometría acústica es un método no invasivo para identificar derrame en el oído medio mediante el reflejo del sonido. Los exámenes de audiometría establecen el grado de afectación en la agudeza auditiva. La timpanometría y la reflectometría acústica deben ser utilizadas cuando la otoscopía neumática no es exacta debido a una exploración difícil o a una anatomía anormal.

\section{Tratamiento médico}

La otitis media aguda es considerada como un problema clínico que requiere de una estrategia adecuada en el manejo y la elección de los antibióticos, ya que su etiología es multifactorial y es difícil diferenciar entre causas bacterianas, virales o no infecciosas. ${ }^{7}$

Es importante hacer notar que existen pocas herramientas que ayuden al pediatra para formular una estrategia adecuada de tratamiento; sin embargo, en recientes revisiones se ha observado que el uso temprano de la terapia antibiótica mejora el curso clínico de la OMA, disminuyendo la sintomatología y la incidencia de complicaciones supurativas como la mastoiditis, ${ }^{8}$ lo cual ha sido reportado en varios metanálisis en niños. ${ }^{9}$

Sin embargo, en la era preantibiótica algunos casos se curaban espontáneamente, pero se observaban, hasta en 3\% de los casos, complicaciones intracraneales serias, lo cual se ha reducido hasta llegar a $0.15 \%$ con la introducción de los antibióticos. ${ }^{10}$

La mayoría de los expertos continúan recomendando la amoxicilina para iniciar el tratamiento empírico de todos los episodios de otitis aguda,; ${ }^{11}$ sin embargo, la acción de ese antibiótico puede llegar a ser limitada, ya que entre 25 y $30 \%$ de los casos presentan organismos productores de betalactamasa. ${ }^{12}$ Otros autores sugieren como tratamiento inicial una droga betalactamasa-estable debido a su costo-efectividad, o bien, por el incremento de organismos amoxicilino-resistentes. ${ }^{*}, 13$

La selección de los antibióticos debe basarse en la concentración de los mismos en el sitio de la infección, lo que a su vez debe estar respaldado por estudios clínicos de control y la erradicación de patógenos aislados del oído medio. ${ }^{14-15}$

En algunas series se utilizan antibióticos de amplio espectro, aunque la superioridad de este tratamiento para una mejoría clínica notoria no es clara; además, su costo es alto, comparado con el de otras drogas asociadas a un menor espectro, como la amoxicilina o el trimetoprim-sulfametoxazol (TMP-SMX). ${ }^{16}$

La administración de ampicilina y amoxicilina en dosis terapéuticas excede la concentración mínima inhibitoria de gram positivos y de la mayoría de cepas de $H$. influenzae, por lo que estos antibióticos son de primera elección, y en los casos de resistencia, se recomienda el uso de TMP-SMX o amoxicilina/clavulanato. ${ }^{17}$

La selección de los antibióticos se simplifica en el cuadro I; la amoxicilina probablemente deba ser la primera elección, seguida por el TMP-SMX (principalmente en pacientes alérgicos a la penicilina) y por la amoxicilina-ácido clavulánico y la cefixina como tercera y cuarta opciones, respectivamente. ${ }^{18}$

El manejo conservador recomienda 10 días de antibioticoterapia, aunque algunos estudios han tenido resultados aceptables con 5-7 días de tratamiento. Cuando

\footnotetext{
* Barché P. Bacterial epidemiology of children with acute otitis media in France. Sixth International Congress of Infectious Diseases; 1994 abril 26-30; Praga, Rep. Checa. Documento no publicado.
}

\section{Cuadro I}

Antibióticos seleccionados en otitis media

Antibióticos

Amoxicilina

Amoxicilina

Amoxicilina clavulanato

Eritromicina sulfisoxasol

Cefixime
Solución (frasco)

$250 \mathrm{mg} / 5 \mathrm{ml}$

$40 \mathrm{mg} / 5 \mathrm{ml}$

$250 \mathrm{mg} / 5 \mathrm{ml}$

$200 \mathrm{mg} / 5 \mathrm{ml}$

$100 \mathrm{mg} / 5 \mathrm{ml}$

N ota: existen otros antibióticos como el cefaclor y el sulfisoxazol
Dosis diaria

$20-40 \mathrm{mg} / \mathrm{kg}$ en 3 dosis

8 - $10 \mathrm{mg} / \mathrm{kg}$ (trimetoprim) en 2 dosis

$20-40 \mathrm{mg} / \mathrm{kg}$ en 3 dosis

$50 \mathrm{mg} / \mathrm{kg}$. (eritromicina)

$8 \mathrm{mg} / \mathrm{kg}$ en $1-2$ dosis 
un paciente no mejora después de 72 horas de manejo con amoxicilina se debe cambiar el antibiótico.

Otras terapéuticas recomendables son: analgésicos, antipiréticos, descongestionantes y antihistamínicos.

Los principales efectos adversos atribuidos al uso de antibióticos se han reportado en $27 \%$ de los pacientes e incluyen diarrea, exantema y eritema perianal. La decisión terapéutica debe anticipar las complicaciones, el costo y el tiempo de administración de los antibióticos. ${ }^{19}$

Los pacientes deben ser reexaminados a las tres o cuatro semanas. Es muy probable que $40 \%$ de ellos aún tenga líquido, pero a los tres meses el porcentaje debe ser menor a 10\%. Es importante asegurarse que el derrame se resuelva, ya que de lo contrario puede ocasionar disminución en la agudeza auditiva y requerir drenaje, profilaxis o adenoidectomía.

\section{Tratamiento quirúrgico}

El tratamiento quirúrgico de la otitis media va desde procedimientos que facilitan el drenaje del oído (miringotomía) y que optimizan la regulación de las presiones en el oído medio (tubos de ventilación) hasta la erradicación total del foco infeccioso (mastoidectomía). ${ }^{20}$

La adenoidectomía, como parte del tratamiento de la otitis media, sigue teniendo un papel polémico; sin embargo, se ha demostrado que con ello la reaparición de derrame en el oído medio disminuye e, incluso, ha habido mejores resultados que cuando se colocan tubos de ventilación.

\section{Miringotomía}

Está indicada cuando se presenta otalgia severa y complicaciones intratemporales o intracraneales de la otitis media $(\mathrm{OM})$, y puede hacerse como intervención exclusiva o junto con la colocación de tubos de ventilación. $^{21}$

\section{Tubos de ventilacion}

Son una opción para el tratamiento de la otitis media recurrente o crónica a la par de la quimioprofilaxis. Son obligados cuando el derrame en oídos es bilateral y persiste por más de cuatro meses, sobre todo en pacientes menores de tres años. ${ }^{22}$

\section{Mastoidectomía}

Está indicada cuando: a) la otorrea persiste pese a que se haya aplicado un tratamiento antibiótico específico por más de dos meses y aun con uso intravenoso; b) se presenta mastoiditis coalescente, y c) se establece mastoiditis crónica.

\section{Complicaciones}

\section{Complicaciones intratemporales}

1. Pérdida auditiva. Es la complicación más común, ya que prácticamente todos los niños que cursan con derrame en el oído medio presentan una pérdida conductiva o neurosensorial que va de 15 a $50 \mathrm{db}$. Ambas pérdidas pueden ser reversibles cuando se resuelve el derrame. Si el evento agudo evoluciona a $\mathrm{OM}$ adhesiva, $\mathrm{OM}$ atelectásica u OM crónica, la pérdida puede ser permanente. Los efectos de la pérdida auditiva no sólo se manifiestan como alteraciones del lenguaje sino también dentro del área psicosocial del niño, pues éste no puede entender ni relacionarse adecuadamente con el medio que le rodea. Por este motivo es crucial asegurarse de que el derrame se ha resuelto tres a cuatro semanas después del episodio agudo. ${ }^{23,24}$

2. Perforación de la membrana timpánica. Siempre que hay otorrea hay una pérdida de continuidad en la MT, la cual puede cerrar en menos de 72 horas. Sin embargo, si esta perforación persiste por más de tres meses, las posibilidades de su remisión espontánea disminuyen y el caso cambia a la cronicidad.

3. Mastoiditis aguda. Las celdillas mastoideas forman parte del oído medio, por lo que es prácticamente regla que una OMA curse con algún grado de mastoiditis. Sin embargo, al haber acumulación de secreción en la cavidad mastoidea con aumento de la presión, ocurre necrosis de las finas trabéculas con la consiguiente coalescencia de pus y formación de abscesos.

El aumento de la presión intracavitaria ocasiona el escape de la secreción purulenta hacia zonas contiguas, las cuales pueden ser la fosa craneal media y posterior, el seno sigmoides y el lateral, el nervio facial, el ápex petroso, los canales semicirculares, o bien, puede pasar a través del área cribosa y ocasionar una miositis, celulitis o hasta un absceso subperióstico, desarrollando lo que clínicamente se conoce como mastoiditis aguda.

En la mastoiditis aguda vemos la clásica protrusión hacia fuera del pabellón auricular, que se puede acompañar o no de otorrea.

Si el pus se colecciona hacia el esternocleidomastoideo, se forma lo que se conoce como absce- 
so de Bezold. Si no hay lisis de las trabéculas óseas, el manejo de esta entidad se hace a base de antibióticos intravenosos, colocación de tubos de ventilación y drenaje del pus retroauricular. Si hay osteítis, el paciente amerita mastoidectomía.

4. Laberintitis. Ocurre cuando la infección penetra el laberinto generalmente a través de la ventana redonda, pero puede ser a través de la ventana oval o incluso por destrucción ósea de los conductos semicirculares en los casos de las otitis crónicas.

Puede ser serosa (con muy buen pronóstico), purulenta (se acompaña de meningitis secundaria en la mayoría de los casos y conlleva una pérdida de la audición permanente) o meningogénica (en este caso el paso de bacterias es a la inversa, es decir, del espacio subaracnoideo al laberinto).

5. Parálisis facial. Es una complicación tanto de la otitis aguda como de la crónica. Los casos agudos se dan por dehiscencia en el acueducto de Falopio; en los casos crónicos la parálisis es secundaria a la lisis de dicho canal con invasión al nervio generalmente por colesteatoma.

6. Colesteatoma. Esta complicación se presenta en las otitis crónicas perforadas; es una acumulación de tejido epitelial de crecimiento rápido que va destruyendo el hueso temporal y su contenido. Amerita tratamiento quirúrgico agresivo una vez que se presenta.

\section{Complicaciones intracraneales}

1. Meningitis. Es la complicación intracraneana más común de la otitis media aguda y se atribuye a diseminación hematógena. Su mortalidad global se notifica en un $10 \%$.

2. Absceso epidural. Ocurre cuando hay destrucción ósea del temporal con acúmulo de pus entre éste y la dura madre. Puede cursar asintomático y su tratamiento es quirúrgico.

3. Empiema subdural. Son raros pero devastadores; se reporta una mortalidad hasta de 50\%.

4. Encefalitis focal otógena. Esta complicación se presenta con edema cerebral o cerebelar focalizado, por lo que hay que hacer diagnóstico diferencial con absceso cerebral. El tratamiento incluye antibiótico y la erradicación quirúrgica del foco otógeno primario.

5. Absceso cerebral. Es una complicación predominantemente de la otitis crónica. También se ha notificado en otitis subagudas, posteriores a meningitis otógena, petrositis o tromboflebitis. Su mortalidad puede ser de hasta $30 \%$.
6. Trombosis del seno lateral. Ocurre cuando la infección penetra el seno; clínicamente se presenta con persistencia de fiebre, escalofríos y datos de hipertensión endocraneana. Puede ocasionar focos sépticos a distancia.

El diagnóstico se confirma con tomografía axial computarizada con medio de contraste o resonancia magnética. Su tratamiento es quirúrgico.

\section{Secuelas}

Si la hipoacusia es la complicación más común de la otitis media, las secuelas de esta patología implican déficit en el desarrollo del lenguaje, ${ }^{25}$ para el cual Nozza demostró que los lactantes requieren de mayor intensidad sonora que los prescolares o adultos en ambientes silentes. ${ }^{26}$

Se ha demostrado también que aun cuando se mejora la audición con tubos de ventilación, los pacientes pueden mostrar todavía alteraciones en la percepción del lenguaje, lo que toma tiempo en normalizarse. Se ha postulado que los mecanismos centrales de la audición bineural no maduran cuando alguno o los dos oídos tienen déficit auditivo.

Feagans y Blood describieron lenguaje poco claro en niños de 24 meses con cuadros de otitis media con derrame ${ }^{25}$ y Luloff encontró que estos pacientes tenían predominantemente problemas al enunciar las consonantes. ${ }^{27}$

Si bien en pruebas psicológicas que miden la inteligencia global no se ha demostrado que los niños con otitis recurrente sean menos inteligentes, sí se ha encontrado que son menos persistentes y atentos, y que muestran menos entusiasmo en sus respuestas en general. ${ }^{28}$

\section{Prevención}

La prevención inicia al ampliar la información entre la población sobre esta enfermedad, de tal modo que evite el consumo de tabaco en el hogar, estimule la alimentación al seno materno y evite el uso del biberón cuando el lactante esté en decúbito. Es importante que la población también sepa que un niño puede cursar con derrame en el oído y estar asintomático.

Una vez que se ha detectado que el paciente tiene tendencia a la recurrencia, los cuadros rinosinusales deben ser erradicados y la valoración del oído debe ser precisa e ir acompañada de neumatoscopía.

El método profiláctico más utilizado es la antibioticoterapia, la cual se indica cuando hay tres o más episodios de OMA en seis meses o cuatro episodios en 
un año. Los antibióticos más usados son: sulfisoxazol (75 mg/ $\mathrm{kg}$ en dos dosis), TMP/SMX una vez al día o amoxicilina, y se administran durante un lapso de tres meses. El uso de las vacunas pneumocóccicas y contra $H$. influenzae no ha reducido significativamente la incidencia de OMA.

Ante la sospecha de hipoacusia se debe realizar un estudio audiológico apropiado para la edad de que se trate. Si la patología persiste pese al tratamiento médico adecuado, el paciente debe ser canalizado al otorrinolaringólogo; cabe recordar que todo paciente con más de tres cuadros de otitis en seis meses o cuatro en un año debe asimismo ser manejado por el especialista. Todos los casos crónicos también deben ser canalizados en el momento de su detección.

\section{Referencias}

1. Lein J,T is M, H ussl B. et al: D efinition and classification of otitis media. Ann 0 tol Rhinol Laryngol, 1989;10 suppl 139:112-115.

2. Bluestone CD.Modern management of otitis media pediatric. C lin N orth Am 1989;36:1371-1375.

3. G riffith TE. Epidemiology of otitis media -An interracial study. Laringoscope 1989;22-25.

4. Davison FW. Middle ear effusions. Laryngoscope 1996;68:1228-1229.

5. Burnstein JA. 0 titis media in children. N Engl J Med 1995;333 (17): 1151-1152.

6. Maxson S, Yamauchi T. Acute otitis media. Pediatr Rev 1996; 17 (6): 191-195.

7. Boccazzi A, Caredn P. Acute otitis media in pediatrics: Are there rational issues for empyric therapy? Pediatr Infect D is J 1997;16 suppl 3: 865-869.

8. Ruskanen 0 , Arola M, Putto-Launla A, Hall J. Acute otitis media and respiratory virus infections. Pediatr Infect Dis J 1989;94-99.

9. Pillsbury HC, Hall JH. O tolaryngol C lin N orth Am 1994; 27:431-441. 10. N iemela M, Uhan M, Jounio-Ervasti K, Moore 0 . Lack of specific symptomatology in children with acute otitis media. Pediatr Infect Dis J 1994; 13:65-68.

11. Harabuchi Y, Faden H, Yamanaka N, Stanievich V, Siven S.G. N asopharyngeal colonization with nontypable Haemophilus influenzae and recurrent otitis media. J Infect D is 1994;170:862-866.

12. Faden H, Stanievich J, Brodsky L, Shurin P, Pelton S, Donner A et al. $C$ hanges in naso pharyngeal flora during otitis media of childhood. Pediatr Infect $D$ is J 1990:9:623-626.
13. Faden H, Doern G. W olf J, Blocker M. Antimicrobial susceptibility of nasopharyngeal isolates of potential pathogens recovered from infants before antibiotic therapy: Implications for the management of otitis media. Pediatr Infect D is J 1994;7:609-612.

14. D el Beccaro MA, Mendelman PM, Inglish AF, Bluestone CD, Stephensen JS, Martin LM.Acute phase reactans in acute bacterial otitis media.Am J Dis Child 1992;146:1037-1039.

15. Arola M, Ruskanen 0 , Z iegler T, Lang R, G oshen S, Raas-Rothschild A et al. Clinical role of respiratory virus infections in acute otitis media. Pediatrics 1990;86:848-855.

16. Rosenfeld RM, Zinkus PW, Gottlieb MV, Shapiro M. Evaluating medical treatment of otitis media. Pediatr Infect D is J 1995;14:731-738.

17. Roselfeld RM, Vertrees JE, Carr J. Clinical efficacy of antimicrobial drugs for acute otitis media: Metaanalysis of 5400 children from thirtythree randomized trials. J Pediatr 1994;124:355-367.

18. Ruff EF, Schotik DA, Bass JW, C larkson R, C hase D, Teele DW .Antimicrobial drug suspension: A blind comparison of taste of fourteen common pediatric drugs. Pediatr Infect Dis I 1991;10:30-33.

19. Maxson S, Yamauchi T. Acute otitis media. Pediatr Rev 1996; 17(6): 191-195.

20. Black N, Sanders CFB, Freeland AP, Vessey MP. A randomized controlled trial of surgery for glue ear. Br Med J 1990;300:1551-1556.

21. Mandel EM, Rockette HE, Bluestone CD, Paradise JL. Myringotomy with and without tympanostomy tubes for chronic otitis media with efusion. Arch 0 tolaryngol Head N eck Surg 1989; 115:1217-1224.

22. Karma P. Finnish approach to the treatment of acute otitis media. Report of the Finnish Consensus Conference. Ann 0 tol Rhinol Laryngol 1987;96 suppl 129:1-19.

23. De Marco S, Fivens $G$. Speech and so und discrimination pre and posttympanostomy a clinical case report. Ear Hear 1989; 10:64-67.

24. N ozza R, Rossman R, Bond L, Miller S. Infant speech sound discrimination in noise. J Acoust Soc Am 1990;87:338-350.

25. Feagans LV, Blood IM. Language and behavioral sequelae of otitis media in infants and young children attending day care centers. En: Lim DJ, Bluestone CD, Klein JO, N elson JD, 0 gra PL, ed. Recent advances in otitis media. Proceedings of the Fifth International Symposium. Hamilton: Decker Periodicals, 1993:521-523.

26. Moore DR, Hutchings ME, Meyer SE. Binaural masking level differences in children with a history of otitis media. Hear Res 1992; 63:71-78.

27. Luloff AK, Menyuk P, Teele DW. Effects of persistent otitis media on the speech sound repertoire of infants. En: Lim DJ, Bluestone CD, Klein JO, N elson JD, 0 gra PL, ed. Recent advances in otitis media. Proceedings of the Fifth International Symposium. Hamilton: Decker Periodicals, 1993: 531-533.

28. Chase D, Teele DW, Klein JO, Rosner L. Behavioral sequelae of otitis media for infants at one year of age and their mothers. Abstracts for the Fifth International Symposium on Recent Advances in 0 titis Media. $\mathrm{H}$ amilton: Decker Periodicals, 1991:187-189 